\title{
Web-GIS application for flood prediction and monitoring
}

\author{
D. Mioc ${ }^{1}$, B. G. Nickerson ${ }^{2}$, F. Anton ${ }^{3}$, D. Fraser ${ }^{1}$,

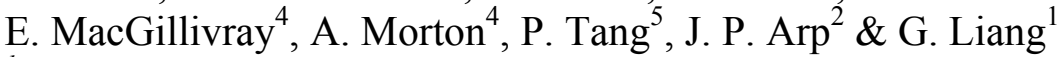 \\ ${ }^{1}$ Department of Geodesy and Geomatics Engineering, \\ University of New Brunswick, Fredericton, Canada \\ ${ }^{2}$ Faculty of Computer Science, University of New Brunswick, \\ Fredericton, Canada \\ ${ }^{3}$ Department of Informatics and Mathematical Modelling, \\ Technical University of Denmark, Lyngby, Denmark \\ ${ }^{4}$ New Brunswick Emergency Measures Organization, \\ Fredericton, Canada \\ ${ }^{5}$ New Brunswick Department of Environment, Fredericton, Canada
}

\begin{abstract}
With global warming and extensive infrastructure development close to rivers, the impacts of flooding events have greatly increased over recent years. To support flood management, early prediction is very useful. In this research, we have developed a decision support system for flood prediction and monitoring that integrates GIS and hydrological modelling with additional bridge sensors and users' observations. Hydrological modelling considers a wide range of information that affect flooding such as snow conditions, temperatures, precipitation patterns, water levels and stream to generate flood predictions. The predicted water levels for the next 24 and 48 hours can be displayed via dynamic web pages, and overlaid with maps of the transportation network, property boundaries, municipal infrastructure and water depth contour lines. In conclusion, this research can provide good flood prediction precision and strong support to the public evacuation if flood events happen.
\end{abstract}

Keywords: dynamic floodplain mapping, flood warning and prediction. 


\section{Introduction}

Flooding disasters are common natural disasters in the world. Each year, they result in much damage to people's properties and sometimes also their lives. In spring 1973, the lower Saint John River in the Fredericton area (New Brunswick, Canada) experienced its worst ever recorded flooding, resulting in economic losses of $\$ 31.9$ million, and leaving one person dead $[1,2]$. At the peak of the flood, private houses and public buildings were flooded, and roads and bridges were damaged [3]. Since 1973 other floods have left another three persons dead and caused more than $\$ 68.9$ millions in damage.

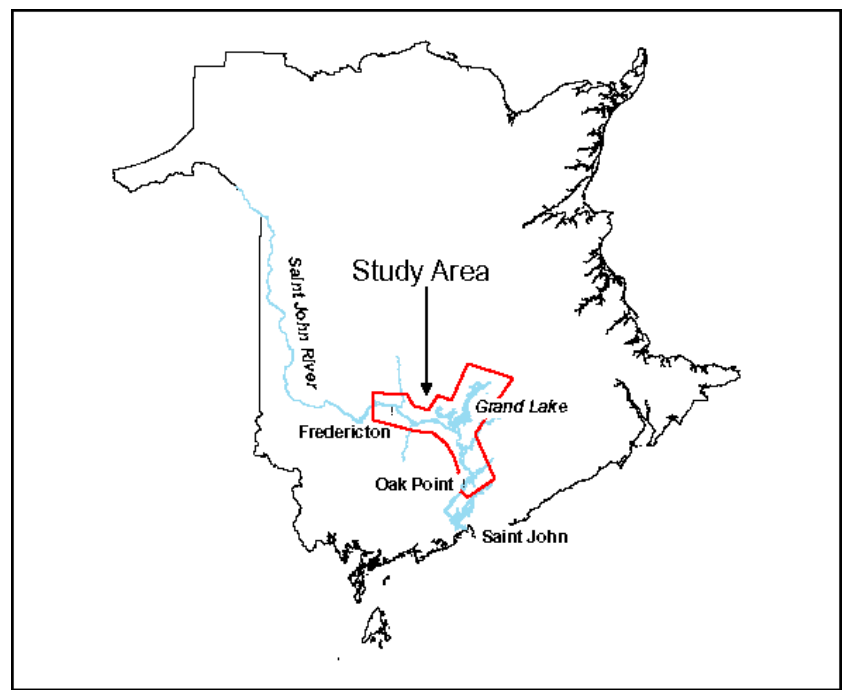

Figure 1: Overview of Saint John River.

The study area of this research (see Figure 1) is the Saint John's flood plain area along a $90 \mathrm{~km}$ long section of the river from Fredericton to Oak Point. Flooding has been a significant problem in this area for some time.

\section{Hydrological modelling}

Flood forecasting on the Saint John River has been carried out by the Hydrology Centre of the New Brunswick Department of Environment with the cooperations of interprovincial and international agencies. Both hydrologic and hydraulic models are utilized in order to forecast water levels in the lower Saint John River. The basic component of the system is the U.S. Army Corps of Engineers' Streamflow Synthesis and Reservoir Regulation (SSARR) model. The Simulated Open Channel Hydraulics (SOCH) model of the Tennessee Valley Authority and the Dynamic Wave Operational (DWOPER) model [4-6] of the National Weather Service are also used. 
The Hydrology Centre monitors the water levels, streamflows and climate with partner agencies, and coordinates a cooperative snow survey with reports for the entire Saint John River Basin. There are networks of 25 streamflow gauges, 16 water level gauges [7], and 43 climate stations throughout the Saint John River Basin. The data is being transmitted to the Hydrology Centre through a variety of telecommunication systems. The data is processed, quality controlled and analyzed before being accepted as input data to the models.

Comparisons of predicted and actual water level observations over the last 10 years have shown that these forecasted river water levels have a $95 \%$ confidence level of $0.2 \mathrm{~m}$. This system therefore has very good flood prediction capabilities [3]. However, the predicted water levels provided by this system cannot satisfy the requirements of the decision support system for flood events. Indeed, they neither directly display the areas affected by flooding, nor show the difference between two flood events. Based on the water levels, it is hard for users to directly determine which houses, roads, and structures will be affected by the predicted flooding. To deal with this problem, it is necessary to interface the output from hydrological modeling to a Geographic Information System (GIS).

In the past decades, hydraulic and hydrologic engineers have developed many methods for delineating floodplain boundaries. Most of these methods are manual, tedious, and labour-intensive. With the advent of robust computer tools and high accuracy Digital Terrain Model (DTM), automated floodplain delineation is achievable [8, 9]. Recently, several management systems for floodplain delineation have been developed and applied in the flood event areas. These include floodplain delineation using watershed Modeling System (WMS) [10], Arc/Info MIKE11_GIS [11], and HEC-GeoRAS [12].

\section{Integration of flood modelling and GIS}

Several provincial and research organisations in New Brunswick (University of New Brunswick, Emergency Measures Organization, NB Department of Environment, etc.) have been actively involved in the project, developing flood modelling software, additional bridge sensor observations and the multi-agent engine for planning best evacuation routes. In this project we used CARIS GIS software to implement floodplain delineation.

\subsection{Floodplain delineation}

Automated floodplain delineation is an excellent tool for producing floodplain extent maps $[8,9]$. In the first step of floodplain delineation, CARIS software is used to generate the TIN model from elevation data.

The basic inputs for automated floodplain delineation are the DTM and the water levels at the cross sections obtained from the water gauges (see Figure 2). The floodplain depth datasets is generated by computing the elevation difference between the water surface TIN (see Figure 3) and the ground surface DTM data. Based on flood depth data, the floodplain extent and flood depth contour maps 


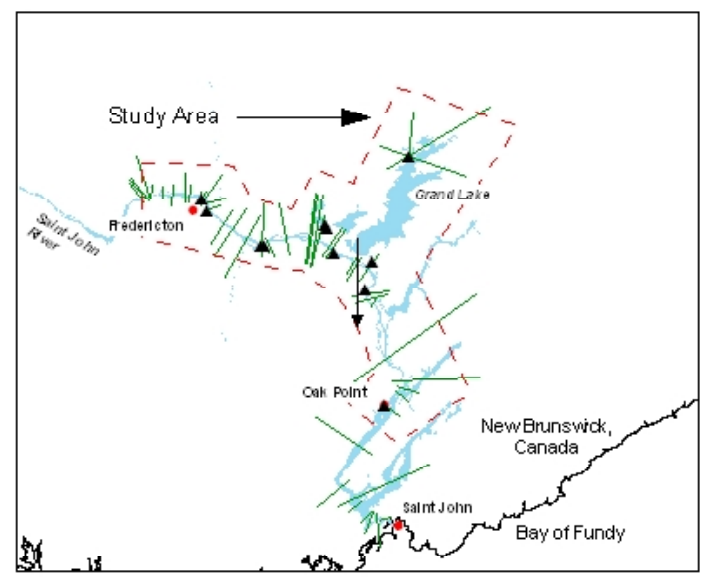

Figure 2: $\quad$ Modelling of water surface using cross sections.

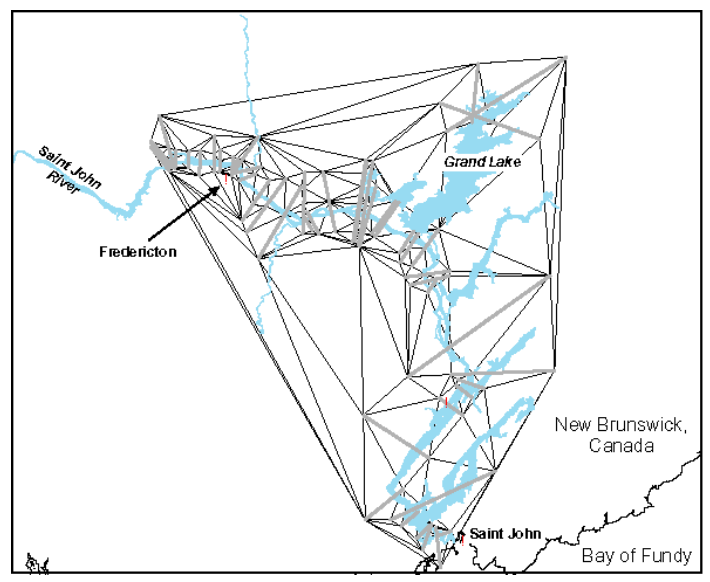

Figure 3: Water surface TIN.

can be generated. The intermediate parts of the process involve geo-referencing the water levels, extending the water levels to the floodplain area, and creating a TIN of the water surface.

CARIS Spatial Fusion is used to develop a Web Map Interface that dynamically displays maps of current and predicted flood events. This Web GIS software has the capability to allow a spatial query based on a 6-digit postal code [13], so the users are able to easily locate their area of interest.

The Web-GIS interface is designed to calculate and display the spatial extent of predicted flood plain (see Figure 4), enabling the visualization of the transportation network, property boundaries, municipal infrastructure, flood polygons and water depth contour lines. 


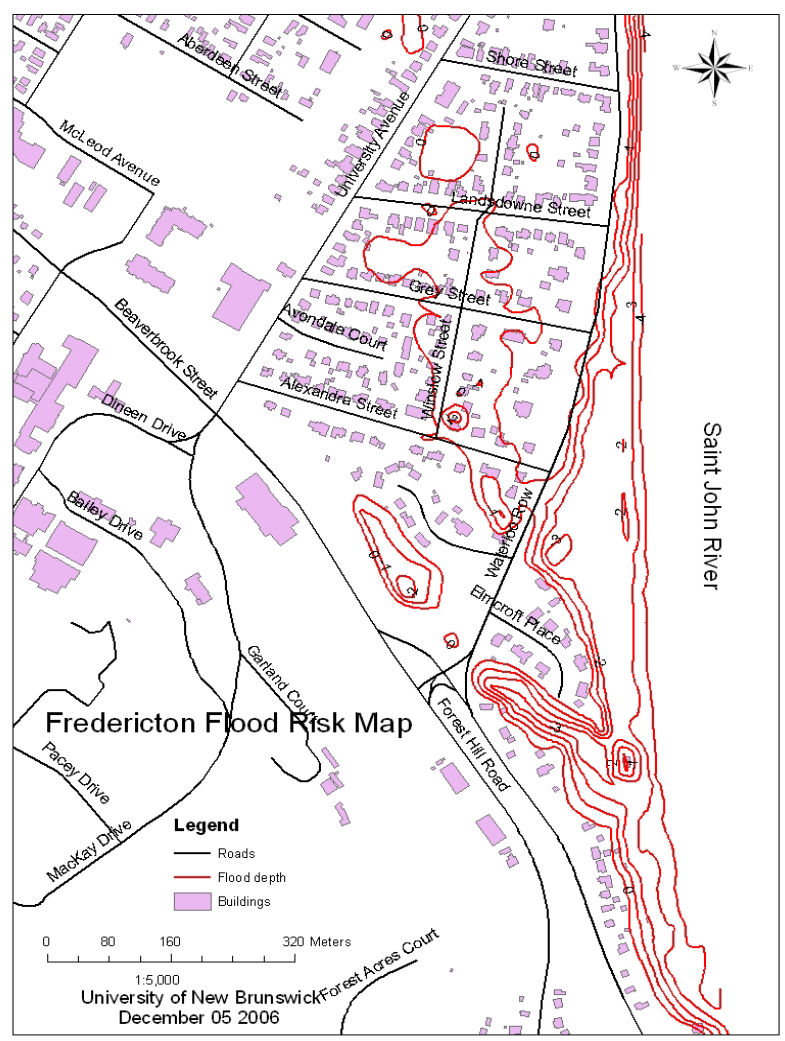

Figure 4: $\quad$ Fredericton flood risk map.

\subsection{Users observations}

This part of the Flood Event Forecast \& Monitoring (FEFM) system provides a useful way for the public to report observations of flooding or near flooding in their neighbourhood. Figure 5 shows the web page of the primary FEFM web page, with the "Your Observations" link in the lower right.

The "Your Observations" input page is shown in Figure 6. Once the "Submit" button is pressed, an e-mail is automatically generated to send the observation to an automated system called the agent-based notification system. A design sketch of this system is illustrated in Figure 7.

A "Your Observation" report at time and date $T_{\mathrm{P}}$ triggers a series of events as shown in the steps below.

1. From the given Canadian six-character postal code, determine the corresponding geographical position (latitude, longitude) $\mathrm{P}=\left(\phi_{\mathrm{P}}, \lambda_{\mathrm{P}}\right)$. The geocoded postal codes for Canada are maintained by Statistics Canada [13], and 


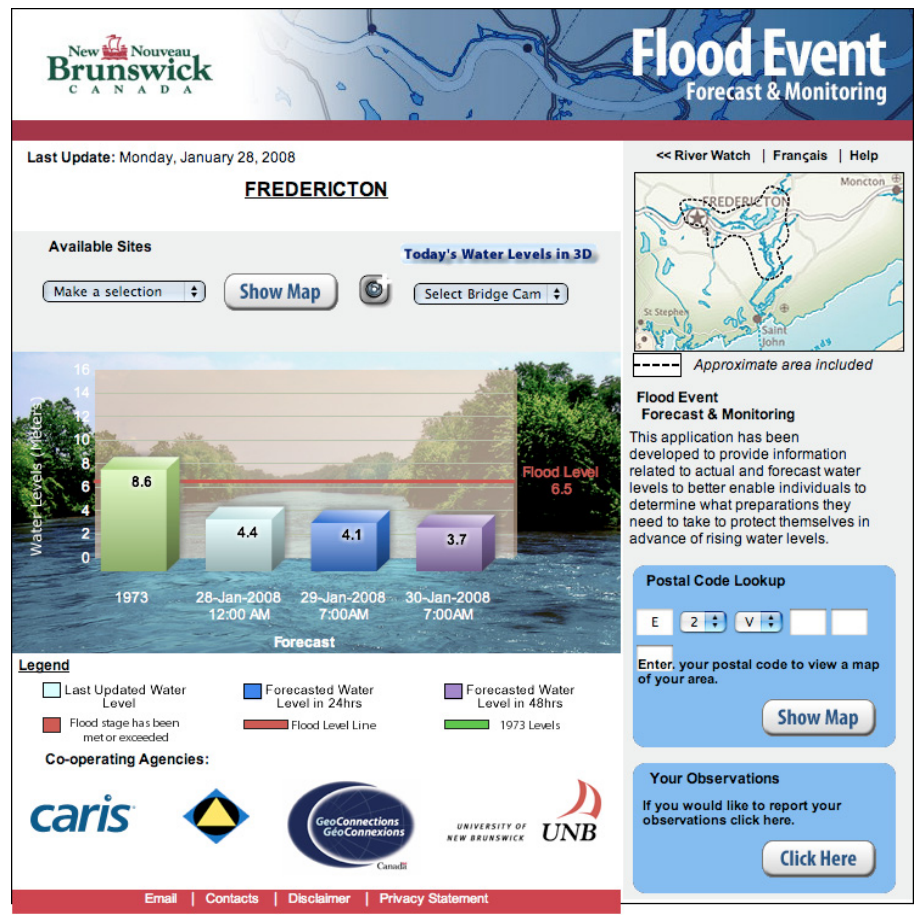

Figure 5: Primary English-language web page of the Flood Event Forecast and Monitoring (FEFM) system. Note the "Your Observations" link in the lower right.

updated on an annual basis. Each postal code specifies a postal delivery area (e.g. one side of a residential street), and its geographical position lies somewhere in this area.

2. Find the two closest water level gauges $G_{1}, G_{2}$ (there are currently 12 gauges in the FEFM area of interest (see e.g. Environment Canada [7]) to P, and obtain the latest water level readings $\mathrm{L}_{1}, \mathrm{~L}_{2}$ (along with the time and date of these observations $\mathrm{T}_{1}, \mathrm{~T}_{2}$ ) from the near real-time water level observation system. Presently, water level gauge observations are recorded approximately once every two hours in our area of interest.

3. Store all parts of the report in a relational database, along with any supplied image and the derived values $\left(\mathrm{P}, \mathrm{T}_{\mathrm{P}}, \mathrm{L}_{1}, \mathrm{~L}_{2}, \mathrm{~T}_{1}, \mathrm{~T}_{2}\right)$.

The above process provides an ongoing record of flood events that can be important "markers" for issuing flood warnings. With the link to near real-time water level gauge readings, we also record the best scientific data about the water levels at the time of the "Your Observations" report. Over time, this event database can be filtered looking for "significant events" that can trigger an elevated emergency response. Perhaps more importantly, the "Your Observations" reporting page provides a way for citizens to directly participate in flood monitoring. 


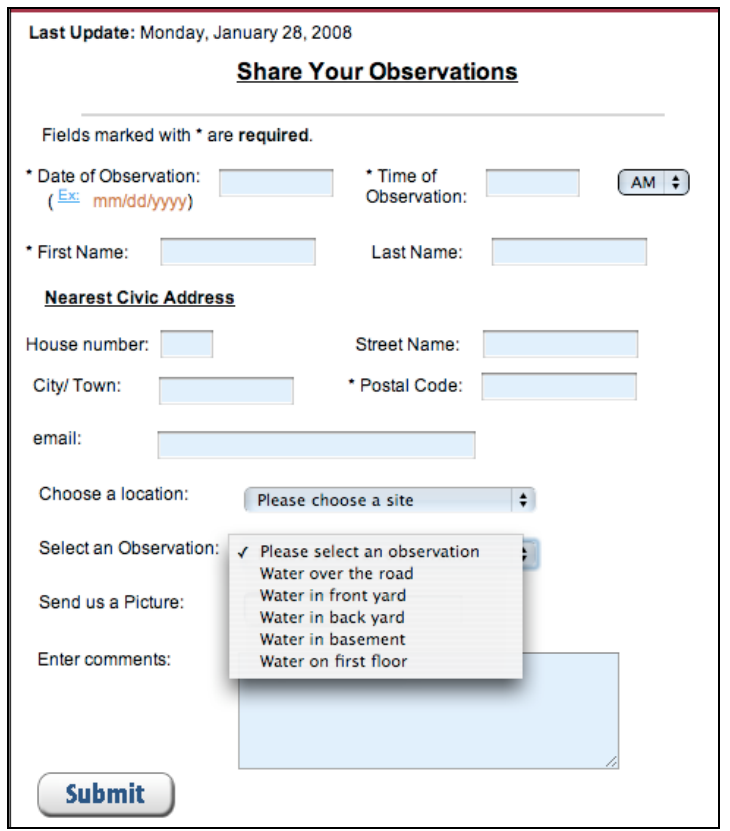

Figure 6: The Your Observations input form for public reporting of flood event observations. The observation must include a six-character postal code and might include a picture of the observed flooding event. Possible locations include the 9 primary flood-prone areas of the area of interest.

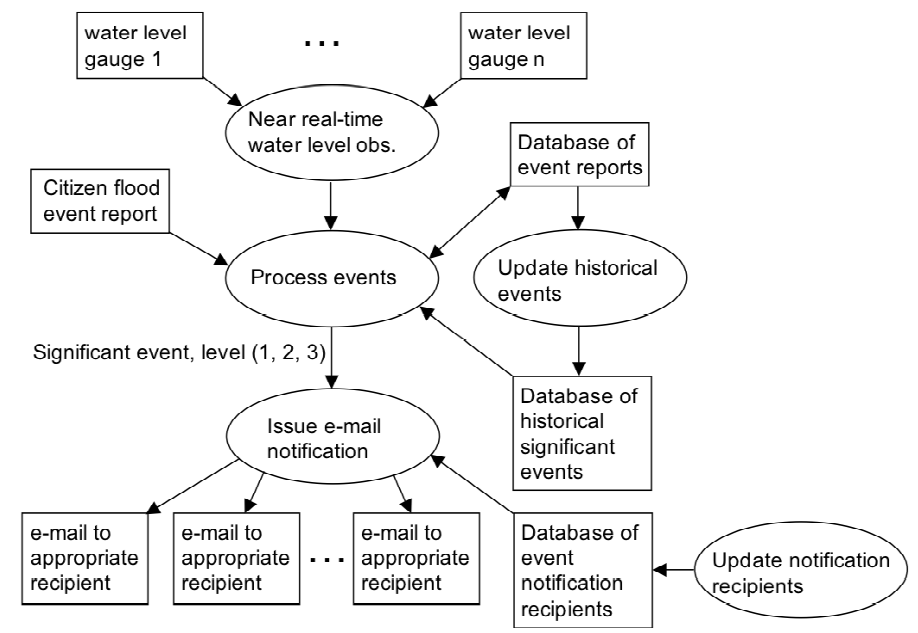

Figure 7: Design sketch of the agent-based notification system for flood event report processing. 


\subsection{Near real-time bridge pier imagery}

As part of the "public awareness" improvement aspects of the FEFM system, we also built and deployed three web camera systems that observe bridge piers continuously [14] on a regularly updated basis (e.g. a new image once every two hours). Figure 8 shows the camera and solar panel beneath the Princess Margaret Bridge.

The primary motivation in building these stand-along bridge pier imaging systems is to provide public awareness of the actual height of the water from recognizable land-marks. Our conjecture is that over time, the "flood-stage" water level imagery will become clearly recognizable in the images, and reinforce the urgency of any "rising water" warnings issued by emergency measures organizations.

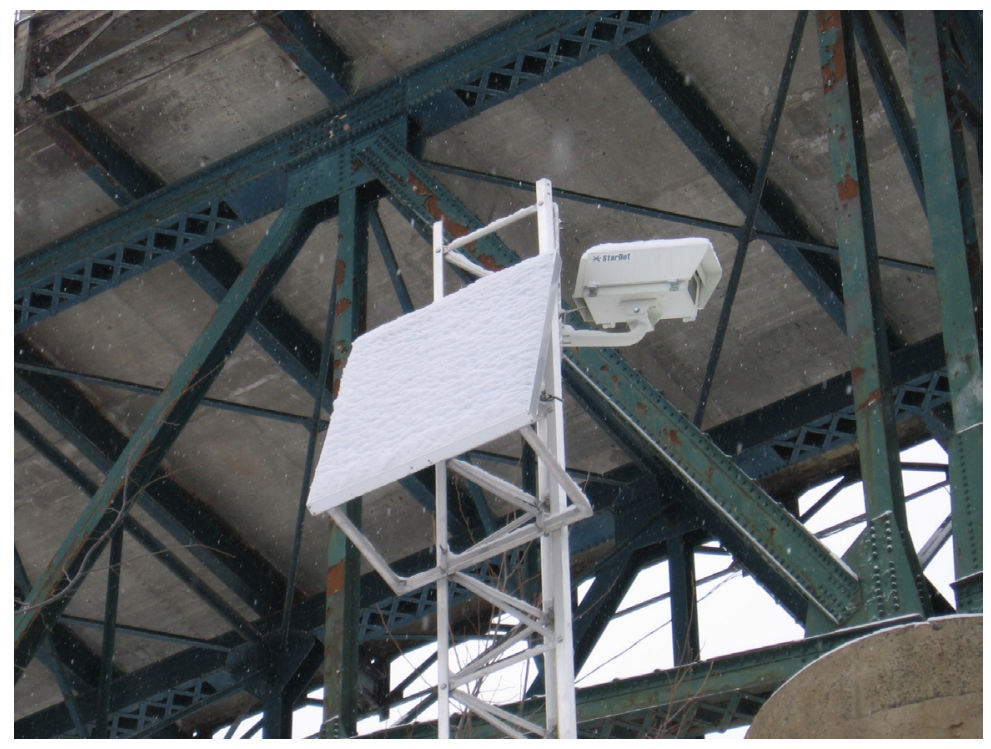

Figure 8: $\quad$ FEFM web camera and solar panel on top of the Princess Margaret Bridge tower.

\section{Conclusions}

In order to deal with the shortcomings of flood prediction using only hydrologic modelling and GIS, we have developed a Web based decision support system for dynamic flood prediction and monitoring. This paper focuses on dynamic floodplain delineation, integration of bridge sensors and users observations and online map interfaces. A Web-based GIS model has been developed to dynamically provide observed and predicted information for decision makers and the general public. The system enables the visualization of the impact of flood events in near-real-time. With satellite imagery and digital elevation model of the 
flood plain area, we can access web-based prediction that models current flood events, and can show how the water progresses based on the output from hydrological modelling for the next 48 hours along the lower Saint John River Valley.

This research will provide the foundation for a revised decision support system that will result in improvements to the prevention, mitigation, response, and recovery from flood events along the lower Saint John River.

\section{Acknowledgements}

The authors would like to acknowledge the generous contribution of time, materials and resources to this project by the New Brunswick Department of Transportation.

Troy Nelson, a Computer Science graduate student, is also acknowledged for his efforts in building the "Your Observation" subsystem.

This project was financially supported, in part, by the N.B. Emergency Measures Organization and by the Canadian Department of Natural Resources Geoconnections program as well as by the University of New Brunswick and the New Brunswick Innovation Foundation (NBIF).

The IT Division of the City of Fredericton provided datasets available for this project. The New Brunswick Department of Environment has provided data and expertise related to hydrological modelling, and the NB Emergency Measures Organization helped with their expertise and additional funding for this project. CARIS provided GIS software used in this project and contributed to the research project by providing the implementation within CARIS Spatial Fusion.

\section{References}

[1] Canada. Inland Waters Directorate. Atlantic Region, New Brunswick Flood, April-May, 1973.

[2] Ottawa: Inland Waters Directorate, Atlantic Region, 1974, pp. 114.

[3] MacLaren Atlantic Limited, New Brunswick. Environment New Brunswick and MacLaren Atlantic Ltd (MAL), Canada-New Brunswick Flood Damage Reduction Program: Hydrotechnical Studies of the Saint John River from McKinley Ferry to Lower Jemseg, Fredericton, pp. 116, 1979.

[4] Fread, D.L., Handbook of Hydrology (Chapter 10), Flow Routing, Editor E.R. Maidment, pp. 10.1-10.36, 1992.

[5] Fread, D.L. \& J. M. Lewis, NWS FLDWAV MODEL: Theoretical description and User documentation, Hydrologic Research Laboratory, Office of Hydrology, National Weather Service (NWS), Sylver Spring, Maryland USA, November, pp. 335, 1998.

[6] Fread, D.L., NWS FLDWAV Model: The Replacement of DAMBRK for Dam-Break Flood Prediction, Dam Safety'93, Proceedings of the $10^{\text {th }}$ Annual ASDSO Conference, Kansas City, Missouri, pp. 177-184, 1993. 
[7] Environment Canada, Water Survey of Canada Hydrometric Program, online http://www.wsc.ec.gc.ca/hydrometric/main_e.cfm?cname=hydro metric_e.cfm.

[8] Noman, N.S., Nelson, E.J., \& Zundel, A.K., Review of automated floodplain delineation from digital terrain models, J. Water Resour. Plann. Manage, 127, pp. 394-402, 2001.

[9] Noman, N.S., Nelson, E.J., \& Zundel, A.K., Improved Process for Floodplain Delineation from Digital Terrain Models, J. Water Resour. Plann. Manage, 129, pp. 427-436, 2003.

[10] Environmental Modeling Research Laboratory (EMRL), Watershed modeling system (WMS) reference manual and tutorial, 1998.

[11] Danish Hydraulic Institute (DHI), MIKE11 - GIS reference and user manual, 2004.

[12] Ackerman, C.T., HEC-GeoRAS GIS Tools for support of HEC-RAS using ArcGIS, pp. 204, 2005.

[13] Statistics Canada, Postal Code Conversion File (PCCF) Reference Guide September 2007 Postal codes, Catalogue no. 92-153-GIE, Issue number 2008001, ISSN 1708-3095, January 2008.

[14] Arp, J.P., and Nickerson, B.G., A User Friendly Toolkit for Building Robust Environmental Sensor Networks, Proc. of the Communication Networks and Services Research Conference, CNSR 2007, May 14-17, Fredericton, N.B., Canada, pp. 76-81, 2007. 